\title{
Integrating Drone Technology with GPS Data Collection to Enhance Forestry Students Interactive Hands-On Field Experiences
}

\author{
Daniel R. Unger ${ }^{1}$, I-Kuai Hung ${ }^{1}$, Yanli Zhang ${ }^{1} \&$ David L. Kulhavy ${ }^{1}$ \\ ${ }^{1}$ Arthur Temple College of Forestry and Agriculture, Stephen F. Austin State University, Nacogdoches, Texas, \\ USA
}

Correspondence: Daniel R. Unger, Arthur Temple College of Forestry and Agriculture, Stephen F. Austin State University, Nacogdoches, Texas, 75962, USA. Tel: 1-936-468-2234. E-mail: unger@ sfasu.edu

Received: June 27, 2018

doi:10.5539/hes.v8n3p49
Accepted: July 6, $2018 \quad$ Online Published: July 19, 2018

URL: https://doi.org/10.5539/hes.v8n3p49

\begin{abstract}
Undergraduate students pursuing a Bachelor of Science in Forestry (BSF) at Stephen F. Austin State University (SFA) within the Arthur Temple College of Forestry and Agriculture (ATCOFA) attend an intensive 6-week hands-on instruction in applied field methods. The second week of field station is focused on land measurement activities to introduce students to practical, hands-on, and technology based ways to survey forest boundaries. On Monday of the second week students are introduced to the concepts of how to use a handheld compass to navigate from point to point, use a consumer-grade handheld Global Positioning System (GPS) unit for collecting the geographic coordinates of given locations, use a GPS unit to calculate the area of a forest opening, use a GPS unit to walk and record a forest hiking trail, and evaluate the accuracy of their GPS derived locations via a Root Mean Square Error (RMSE) analysis. RMSE analysis between a students collected geographic coordinates and the instructors collected geographic coordinates indicated that the students were sufficient in correctly recording the geographic coordinates of point, line, and polygon features identified in the field. Grades on the student submitted reports summarizing Monday's activities resulted in 33 of 56 students (59.0\%) receiving a high A, 14 of 56 students (25.0\%) receiving a low A, and 9 of 56 students (16.0\%) receiving a high B indicating that the interactive hands-on nature of ATCOFA's field station is effective at providing students with real-world applications whereby they will be ready to make a difference the day after graduation. Interactive drone imagery and video integrated into the daily activities in the field to enhance a student's understanding of their specific objectives provided the students in the field with a bird's eye perspective of the landscape to aid their understanding and planning of the field tasks assigned. In conclusion, employers can have confidence that when hiring recent BSF graduates from ATCOFA that the students have been introduced to geospatial technologies within a proven one-on-one instruction methodology designed to increase cognitive retention and can traverse from location to location accurately and record the geographic coordinates of earth surface features correctly.
\end{abstract}

Keywords: accuracy, GPS, drone, forest, RMSE

\section{Introduction}

At the end of their sophomore year students pursuing a Bachelor of Science in Forestry (BSF) degree within the Arthur Temple College of Forestry and Agriculture (ATCOFA) at Stephen F. Austin State University (SFA) attend an interactive hands-on field station. The field station, which consists of all students majoring in forestry, wildlife, and recreation, is intended to introduce students to the hands-on aspect of forest management via an intensive all day focus on applied field activities not attainable during a normal academic semester lecture format (Unger, Hung, Zhang, \& Kulhavy, 2014).

Students who attend ATCOFA have stated they do so because they have chosen to pursue a career path based on three main items of concern: they want to make a difference in the world, they would prefer to work outdoors, and they want to use high end technology throughout their careers. To facilitate those objectives undergraduate coursework within ATCOFA accredited by the Society of American Foresters (Society of American Foresters, 2011) focuses on hands-on instruction, field exercises, and real-world applications to produce society ready foresters who are ready to make a difference the day after graduation (Bullard et al., 2014).

Although the field station is housed on the campus of SFA, the students typically meet in a lecture room the 
night before and early in the morning for a summary of each day's activities and then are driven out into the field to complete each day's hands-on activities. The six week field station is divided between faculty members within ATCOFA and consists of instruction in six main areas; recreation and human dimensions, land measurement, biometrics, wildlife, silviculture, and industry tours. Upon returning at the end of each day students are expected to write detailed reports summarizing their daily activities including an emphasis on what they learned and how it will enhance their future careers.

The second week of field station is focused on land measurement activities. The students meet with the instructors starting at 5:00 p.m. Sunday night of week two for a quick introduction to the week followed by nighttime instruction detailing what will be expected on Monday; this typically will last until approximately 9:00 p.m. or until the last student is certain that they have mastered what will be expected on Monday. On Sunday night each student is given a detailed diagram depicting the field and office interaction expected for the week (Table 1). Starting Monday morning at 7:00 a.m. the students are driven to the field site for the day to complete the days assignments in groups of 4 to 5 students per group to facilitate data collection and to increase communication and learning between group members. Approximately early afternoon, depending on when the students have completed their daily tasks, they are driven back to the SFA campus to work on their reports in ATCOFA's geographic information system (GIS) labs which are due the next morning at 7:00 a.m. prior to leaving for the field the next day.

Starting at 7:00 p.m. Monday night the students will reconvene in the lecture room to discuss and prepare for the exercises they will complete in the field on Tuesday; this will typically run until 9:00 p.m. or later depending on student participation and how long it takes the students to grasp the next day's topic. The process of returning to SFA campus in early afternoon to work on their reports due the next morning at 7:00 a.m. and returning the same day for the next day's night time lecture preparation at 7:00 p.m. continues for Tuesday, Wednesday, and Thursday. At 7:00 p.m. Thursday night in lieu of prepping for field exercises on Friday the lecture time is devoted to reviewing the topics introduced during the week and preparing for exams all day Friday. Starting at 7:00 a.m. Friday morning students are tested individually on the equipment they used during the week to complete their exercises to evaluate their hands-on learning; starting at 2:00 p.m. on Friday the students are given a written test in short answer format to evaluate their intellectual comprehension of the weeks activities.

The focus of the land measurement week is to introduce students to practical, hands-on, and technology based ways to survey forest boundaries (Unger et al., 2013) and consists of one semester hour of credit. Program learning outcomes indicate that at the end of the week the student will demonstrate proficiency in understanding how to survey for the creation of a small pond, how to traverse the landscape with a compass and pacing, how to collect waypoints with a basic GPS unit, how to survey a track of land with a staff compass, how to use high end GPS units in a forest inventory, and how to create an elevation profile of a track of land.

The topic for Monday's exercises for the land measurement week, which is the focus of this paper, is titled Compass Traverse and GPS. During Monday of the land measurement week the students learn how to use a handheld compass to navigate from point to point, use a consumer-grade handheld Global Position System (GPS) unit for collecting the geographic coordinates of given locations and save them as a point feature, use a GPS unit to calculate the area of a forest opening and save the opening as a polygon, use a GPS unit to walk and record a forest hiking trail as a linear feature, and evaluate the accuracy of their GPS units.

A forestry student knowing how to use a GPS unit to derive the geographic coordinates of a point feature (e.g. tree, bear den), linear feature (e.g. stream, trail), or polygon feature (e.g. lake, forest boundary) is crucial to the understanding and proper management of any forest resource. (Clarke, 2003; Heit \& Shortreid, 1991; Lang, 1988). The accuracy of consumer-grade GPS units can vary and researchers have found that some consumer-grade units accuracy of any derived geographic feature location can be affected by the density of forest cover and the size of trees (Piedallu \& Gegout, 2005). In addition Zheng, Wang, and Nihan (2005) evaluated the static performance of a mapping grade GPS unit under three different canopy closure levels in the Pacific Northwest and found that canopy density can significantly affect the positional accuracy of GPS receivers at the $\mathrm{p}=0.01$ level. 
Table 1. Diagram depicting the field and office interaction expected of the students for the week

\begin{tabular}{|c|c|c|c|c|c|c|}
\hline \multicolumn{7}{|c|}{ FOR 323 Land Measurement Weekly Outline } \\
\hline Time & Sunday & Monday & Tuesday & Wednesday & Thursday & Friday \\
\hline 7:00 AM & & Field Compass & Field & Field Pond & Field Stand & Interactive \\
\hline 8:00 AM & & $\begin{array}{c}\text { Traverse and } \\
\text { GPS }\end{array}$ & $\begin{array}{l}\text { Differential } \\
\text { and Profile } \\
\text { Leveling }\end{array}$ & Design & $\begin{array}{c}\text { Boundary and } \\
\text { FIA Plot } \\
\text { Surveys }\end{array}$ & Field Test \\
\hline 9:00 AM & & & & & & \\
\hline 10:00 AM & & & & & & \\
\hline 11:00 AM & & & & & & \\
\hline 12:00 PM & & & & & & \\
\hline 1:00 PM & & Office Work & Office Work & Office Work & Office Work & \\
\hline 2:00 PM & & and Report & and Report & and Report & and Report & Individual \\
\hline 3:00 PM & & Generation & & & Generation & \\
\hline 4:00 PM & & & & & & \\
\hline 5:00 PM & Assemble & Dinner Break & Dinner Break & Dinner Break & Dinner Break & \\
\hline 6:00 PM & Night Lecture & & & & & \\
\hline 7:00 PM & Night Lecture & Night Lecture & Night Lecture & Night Lecture & Review & \\
\hline 8:00 PM & Night Lecture & Night Lecture & Night Lecture & Night Lecture & Review & \\
\hline
\end{tabular}

In addition to introducing forestry students at ATCOFA in the proper use of GPS units to survey forest land the faculty are also highly involved in integrating Unmanned Aerial Systems (UASs), also known as drones, into the undergraduate curriculum. A drone, which can be flown from ground level up to an altitude of 400 feet, can provide an instructor and the students with a perspective of the land not attainable from ground level. The drone can acquire high resolution images and videos that can be viewed interactively in the field to facilitate data collection and/or stored for later use in training or instruction (Kulhavy et al., 2016; Kulhavy, Unger, Hung, \& Zhang, 2016; Unger, Kulhavy, Busch-Petersen, \& Hung, 2016). This additional high-end technology tool can be used remotely in the field to make forest boundary assessment easier for the student as well as help the instructor keep an eye on students from above that are either too physically far away to be seen or hidden by ground level visual obstructions.

The objective of this paper is to present how faculty within ATCOFA are introducing forestry students within an interactive hands-on field based teaching exercise how to accurately map geographic coordinates of point, line, and area features in a forest setting using consumer-grade GPS units. In addition, the use of drone technology to facilitate hands-on student instruction and aid faculty keep an eye on students at remote locations in the field and use the imagery and videos later to enhance future instruction is presented.

\section{Methods}

ATCOFA forestry students, during the Monday portion of the land measurement week at field station, were trained how to properly map the geographic coordinates of point, line, and area features in a forest setting using consumer-grade GPS units. During the Monday field exercises the students were shown how high-end drone technology can be used in a forest setting to facilitate field data collection by providing students access to images and videos from a drone providing students additional information from a vertical perspective to help them plan their daily exercises. Students were also introduced how to assess the accuracy of their GPS units at the end of their exercises Monday afternoon.

Field station is based out of the ATCOFA main building on the campus of SFA in a general lecture room. The location for Monday's field exercises was at the ATCOFA beef farm located 11 miles north of the SFA campus in Nacogdoches County, Texas (Figure 1). The forested area of the beef farm consists of a mix of forest openings, open pasture, pine forest, hardwood forest, mixed pine-hardwood forest, and a small agriculture pond. The location is perfectly suited to train future forest resource professionals in a variety of forest settings.

\subsection{Preparing the Compass Traverse and GPS Data Collection}

On Sunday night, and prior to going to the field Monday morning, students were assigned to individual groups of 4 or 5 individuals per group and introduced to the concept of how to use a compass and pacing to traverse from point A to point B in the field based on points labelled on a map they would be given Monday morning. Students 
were instructed how to adjust their compass for magnetic declination, how to use map scale to calculate real-world distance between two points, and how to determine true north on any map using a linear map feature as reference. The students were then instructed how to use a compass with a map to determine the azimuth between two identified map locations and calculate the ground distance between the two identified map features.

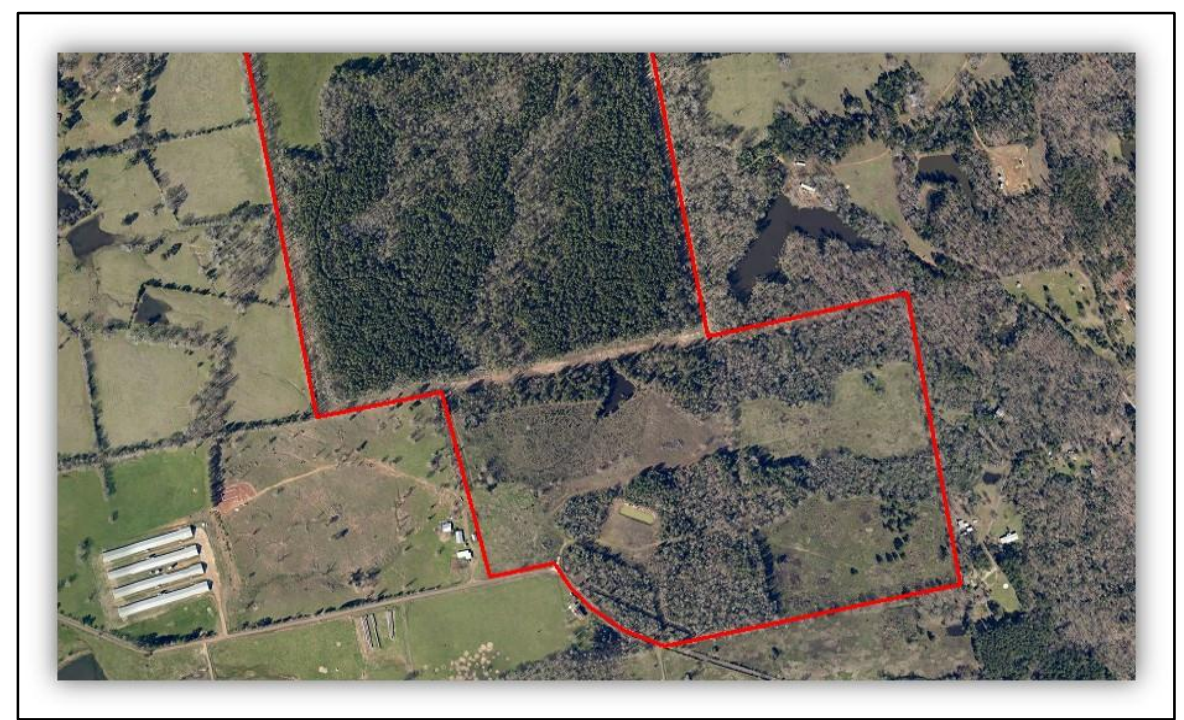

Figure 1. Location of Monday's land measurement exercises identified inside red boundary at SFA's beef farm

Students were then instructed that in the morning they would be dropped off at a known point near the beef farm and provided a map of the area Monday morning with 14 labelled points that they would traverse to using only their compass and pacing skills. At the ground location of each identified map point the instructors installed 3 wooden stakes that were colored blue, green, and red. The 3 wooden stakes per point location were installed approximately 30 - 50 feet from each other in random cardinal directions. Three different maps of the beef farm with 14 labelled points per map were randomly assigned to each group to ensure that the students would be forced to trust their pacing skills and not simply following other groups to a colored stake. For each of the 3 individual maps of stake locations, the color of each assigned wooden stake per point location per group was also randomly assigned to ensure that groups did not simply look for a consistent color of stake but rather trust their pacing skills. Therefore, if a group did not measure the distance between points correctly or were off with the compass direction there was a 66 percent chance of being at the wrong location (Figure 2).

After reviewing the use of pacing with a compass, the students were instructed how to use the GPS units assigned per person. Each person was given a Garmin eTrex Legend HCx, Garmin eTrex 30, or Garmin eTrex Touch 25 GPS unit. These units were provided to introduce the students to a basic and effective GPS unit proven useful by practicing foresters for their ease of use, consumer-grade off the shelf availability, practicality, and affordability ( \$200). Once handed out each student was shown how to set their individual GPS unit to collect data in the Universal Transverse Mercator (UTM) coordinate system for consistency between groups and to enable their units to collect geographic coordinates with real-time differential correction using WASS (to ensure the highest level of accuracy). After changing the settings on their GPS units, the students were taken outside to prepare for Monday morning. Students rotated between three locations identified outside the main ATCOFA building at SFA where the instructors were located to help each student individually how to navigate with a compass by determining the azimuth between two identified map points, how to use scale to calculate ground distance between two points and how to use a GPS unit to collect the geographic location of point, line, and polygon features (Figure 3). The class for the night ended after each student showed proficiency in data collection.

\subsection{Field Data Collection (Compass Traverse and GPS Point Collection)}

Starting Monday morning at 7:00 a.m. the student groups, staggered in 20 minute leave intervals to minimize clusters of students at one location if they all started at the same time, were driven out to a road near the beef farm where they recorded the azimuth of the road. Each group of students was then provided a map of the beef farm with 14 labelled points they would navigate to and record the geographic coordinates of the randomly 
assigned wooden stake closest to the ending point of their paced transect. Once each group had been given their randomly assigned map the student groups were driven to 2 identified drop off points in the forested area of the beef farm (Figure 4).

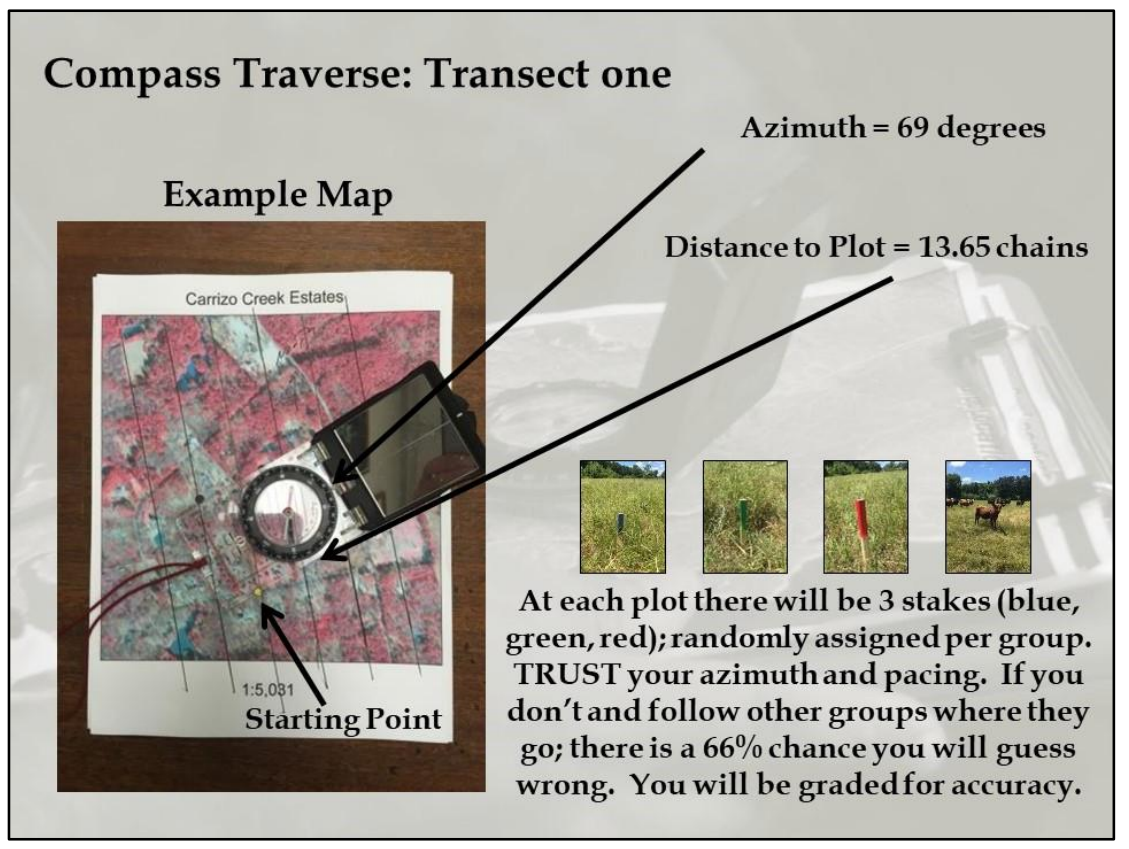

Figure 2. PowerPoint slide showing students how to use a compass to determine direction and distance; the wooden stakes they navigated to are also displayed

\section{Sunday night outside prep}

- Drop Off Compass

Preparation (Unger/Tiller, A)

- eTrex Legend HCx Preparation (Hung, B)

- eTrex 30 Preparation (Zhang, C)

- Unger/Tiller will move to $B$ and $\mathrm{C}$ following completion of $A$

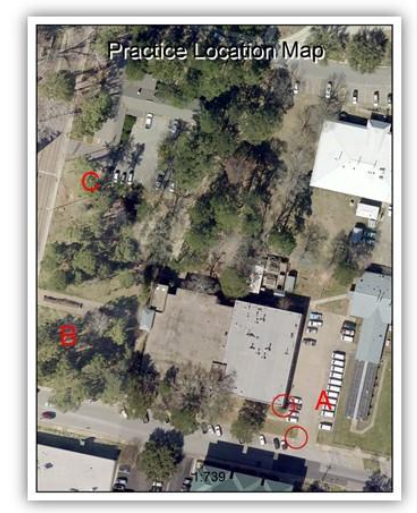

Figure 3. PowerPoint slide showing students where to go outside the main ATCOFA building for practice on Monday night 


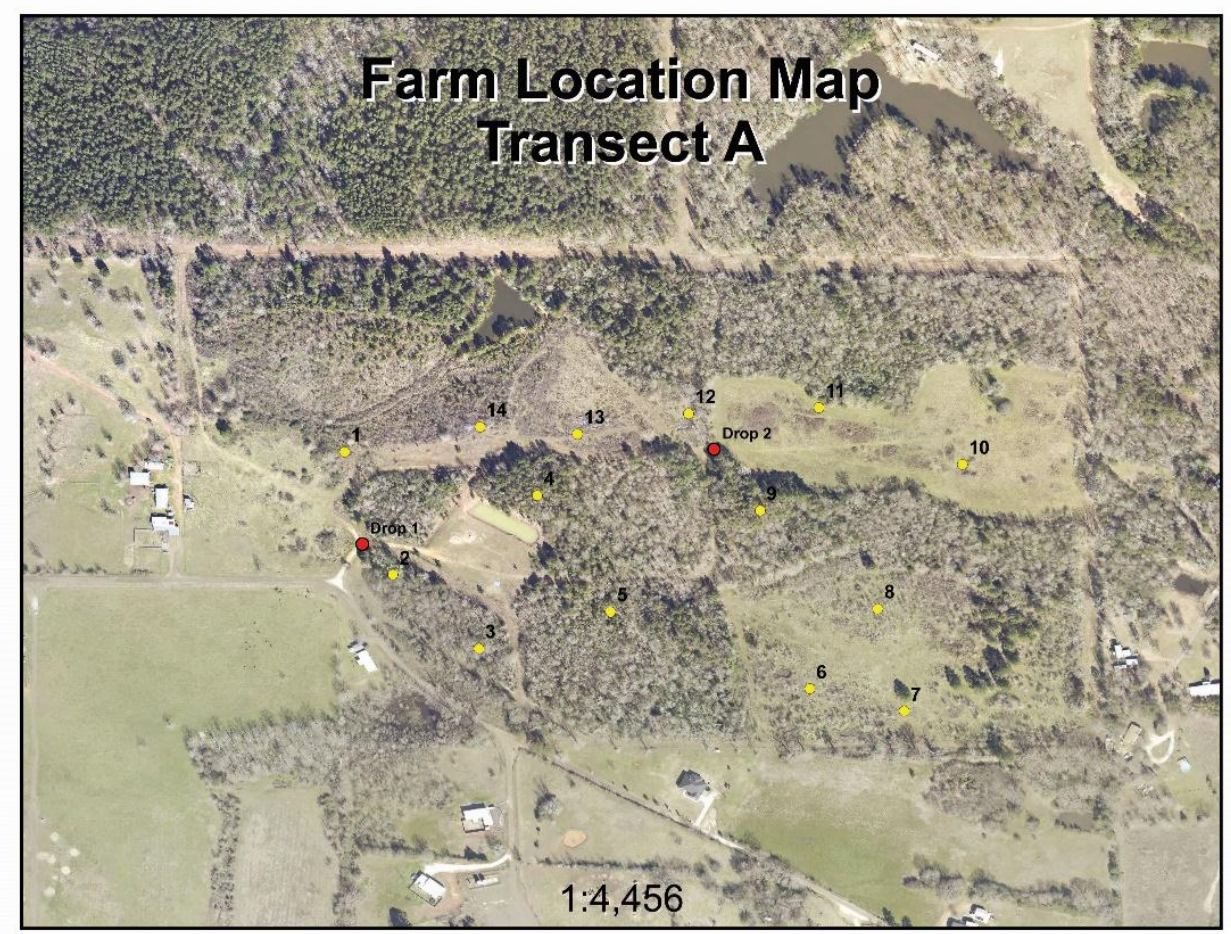

Figure 4. Example of a map with 14 labelled points assigned to a group

After arriving at their designated drop point in the beef farm the student groups identify true north per map per group based on the road azimuth measured. After identifying true north, the students with the instructors help identified the best path to walk from point location to point location and recorded the azimuth and distance between each successive transect between two points. A DJI Phantom 4 Advanced drone (Da-Jiang Innovations Science and Technology Co., Ltd., Shenzen, China) was used to capture still images and video of the interactive hands-on portion of setting up a transect course in the field for future instructional purposes and to demonstrate to the students how a drone can be used to capture spatial information remotely (Figure 5).

Aspects of the drone including safe operation and regulations of both Federal Aviation Administration (FAA) rule 336 and FAA rule107 (FAA 2016a; FAA 2016b; FAA 2018) were presented to the students (Watts, Ambrosia, \& Hinkley, 2012). It requires that the drone is flown by line of sight with a maximum altitude of 400 feet above ground level, has a pilot in command with a visual observer, must be flown during daylight, and weighs less than $55 \mathrm{lbs}$. FAA rule 336 is the Special Rule for Model Aircraft and students can learn to fly using this regulation. Students wising to earn a drone pilot license under FAA rule 107 can enroll in a training course to both prepare for the FAA drone examination and to learn how to fly a drone.

Once the azimuth and distance between all points had been determined, the students walked from point to point location using their compass to follow a known azimuth line and their ability to pace accurately between two locations (Figure 6). Upon arriving at the end of each walked transect line, the students identified the closest wooden stake at the end of their transect line. Once identified, each student used their assigned GPS unit to record the average UTM coordinates in meters (Easting, Northing) of the identified wooden stake (Figure 7). Drone imagery of students walking a transect line and recording average UTM coordinates for a wooden stake were acquire using the DJI Phantom 4 Advanced drone from a distance of over 1000 feet away to demonstrate the utility to monitor student activity remotely in the field. Since student groups were staggered to minimize clustering of students, the interactive drone imagery was shown to individual groups sequentially at their assigned drop point to reinforce what they would be doing and to give them a birds eye perspective of the landscape to facilitate how they planned their transects.

After Monday's field exercises, the students compared their average UTM coordinates of each identified point with the average UTM coordinate of the wooden stake that each group should have reached at the end of each of their transect lines. The accuracy of the student point coordinates were assessed by calculating RMSE between student point coordinates and coordinates of the wooden stake that each group should have reached (Equation 1). 


$$
R M S E=\sqrt{\frac{\sum_{i=1}^{n}\left[\left(x_{i, \text { student }}-x_{i, \text { instructor }}\right)^{2}+\left(y_{i, \text { student }}-y_{i, \text { instructor }}\right)^{2}\right]}{n}}
$$

RMSE was utilized so the students could evaluate and quantify the effectiveness of their ability to acquire accurate real-world coordinates.

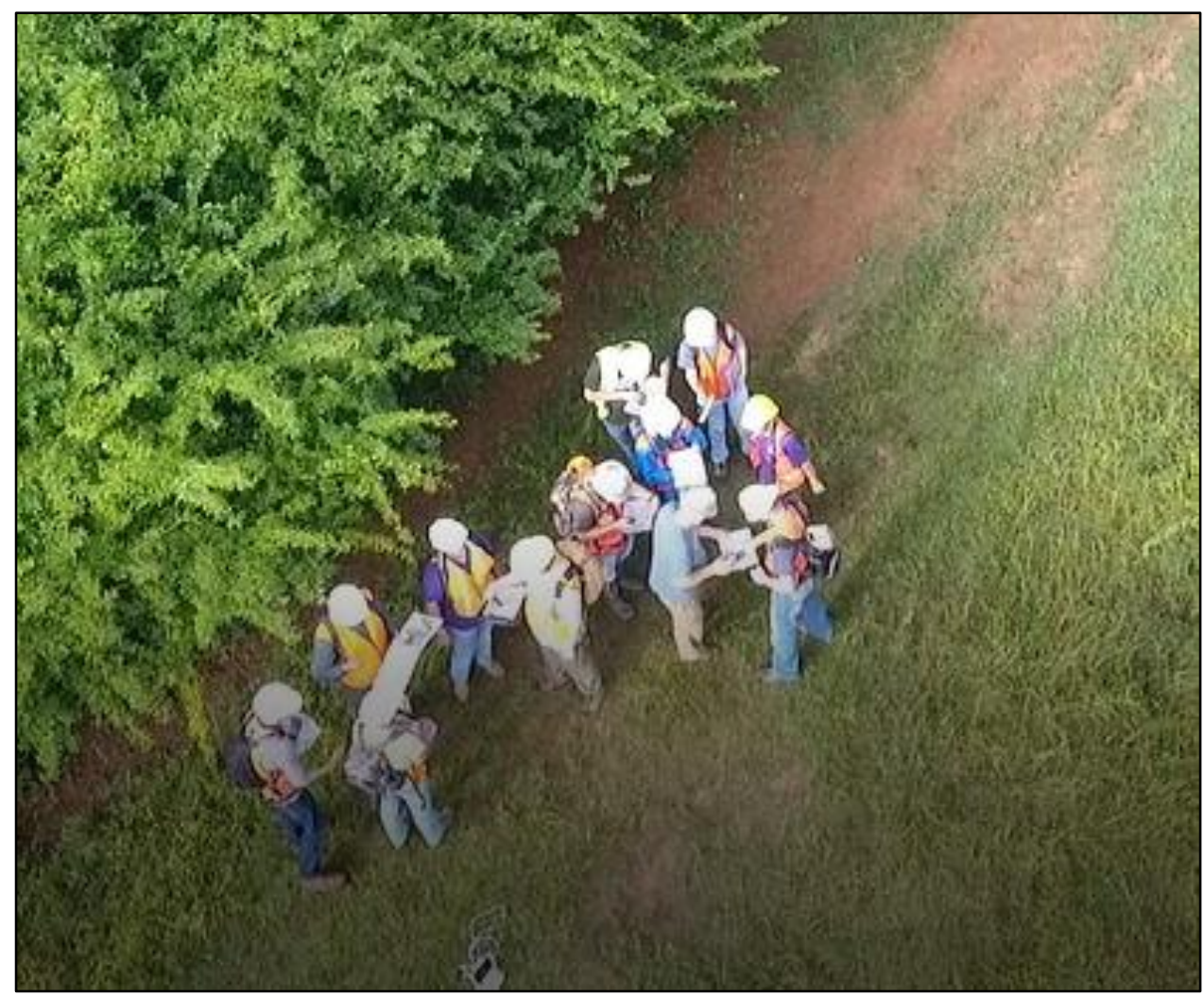

Figure 5. Aerial perspective from the DJI Phantom 4 Advanced drone of students identifying distance and azimuth between two map locations with the aid of a faculty member

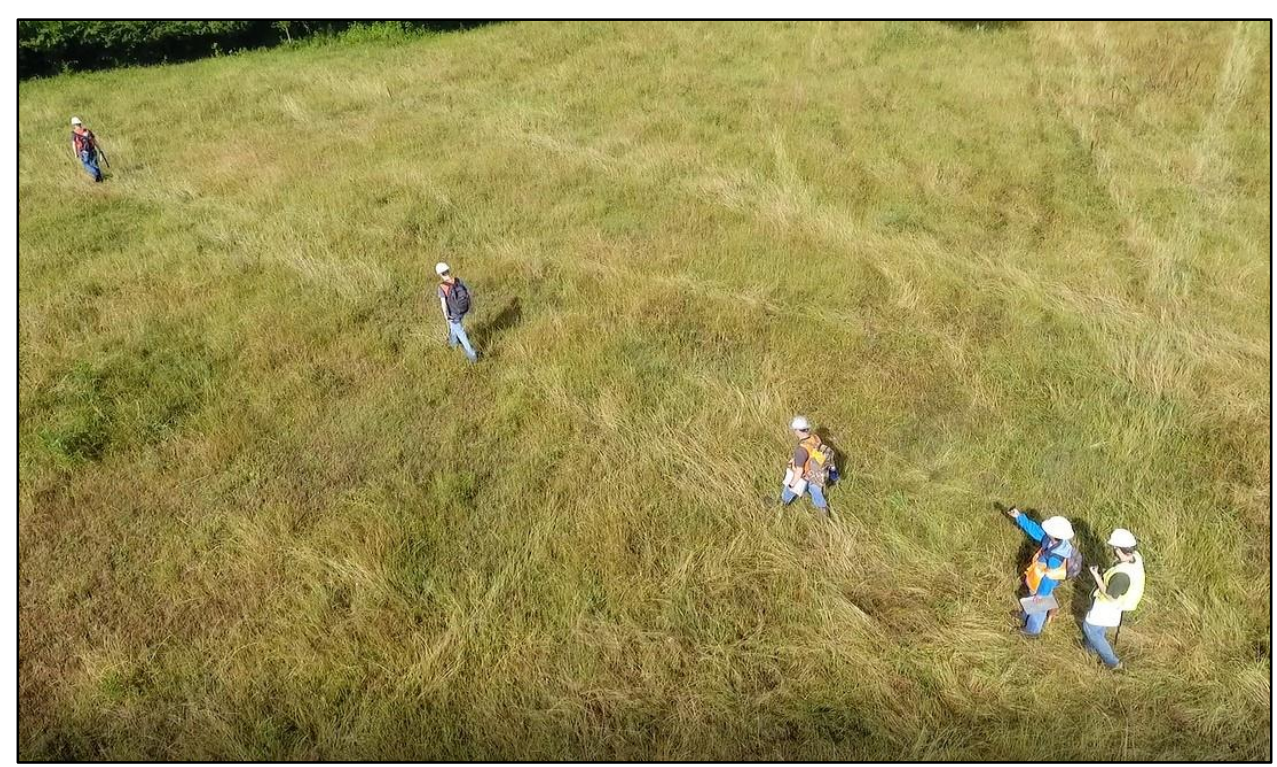

Figure 6. Aerial perspective from the DJI Phantom 4 Advanced drone of students walking a transect line between two point locations 


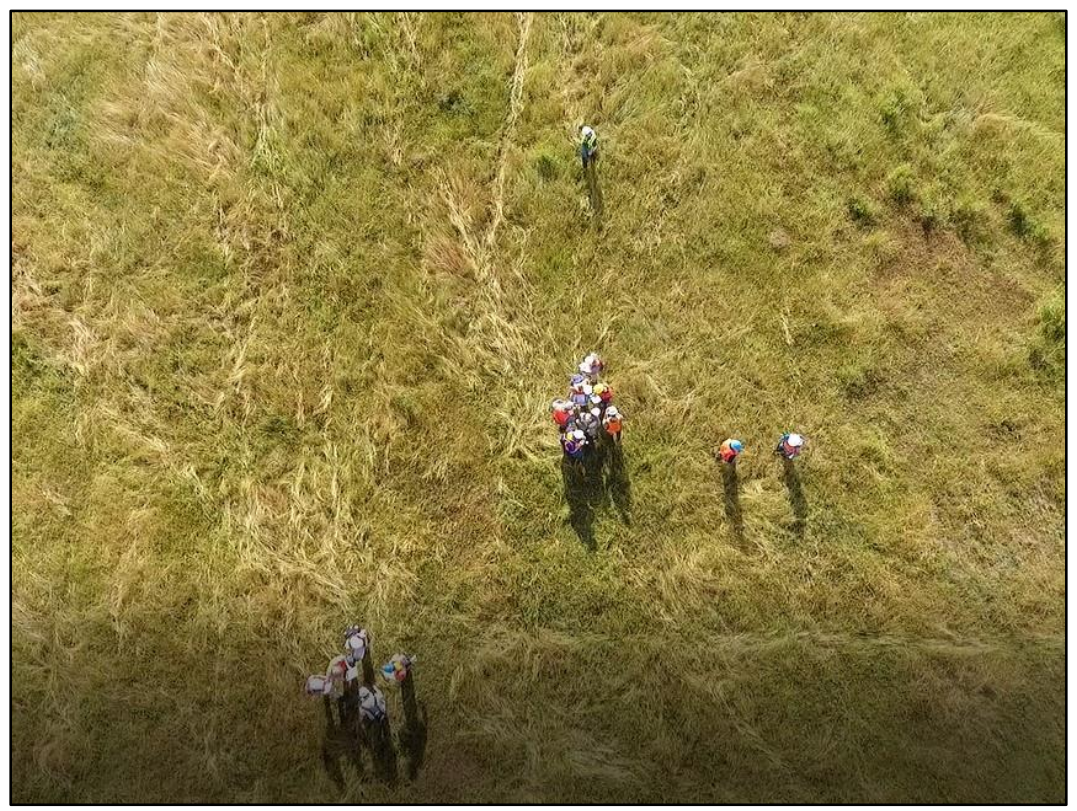

Figure 7. Aerial perspective from the DJI Phantom 4 Advanced drone of students recording the average UTM coordinates of an identified wooden stake

\subsection{Field Data Collection (GPS Area Collection)}

After the students collected the average UTM coordinates in meters of the 14 point locations, the students were shown via interactive drone imagery the forest edge they needed to walk to calculate the acreage and record the polygon of a forest opening in the beef farm (Figure 8). Each student then identified a starting point for a GPS recorded track for the forest opening and walked the forest edge; returning to the starting point and saved the polygon of the forest opening as a track to be used later in the GIS labs to create a polygon of the area.

\subsection{Field Data Collection (GPS Linear Collection)}

After the students collected the track/polygon of the forest opening, the students were shown via interactive drone imagery the hiking trail they needed to walk to calculate the length and record the hiking trail as a linear feature in the beef farm (Figure 9). Each student then identified a starting point for a GPS recorded track for the hiking trail and walked the trail until it met the small agriculture pond; each student recorded the hiking trail as a track to be used later in the GIS labs to create a linear feature of the hiking trail.

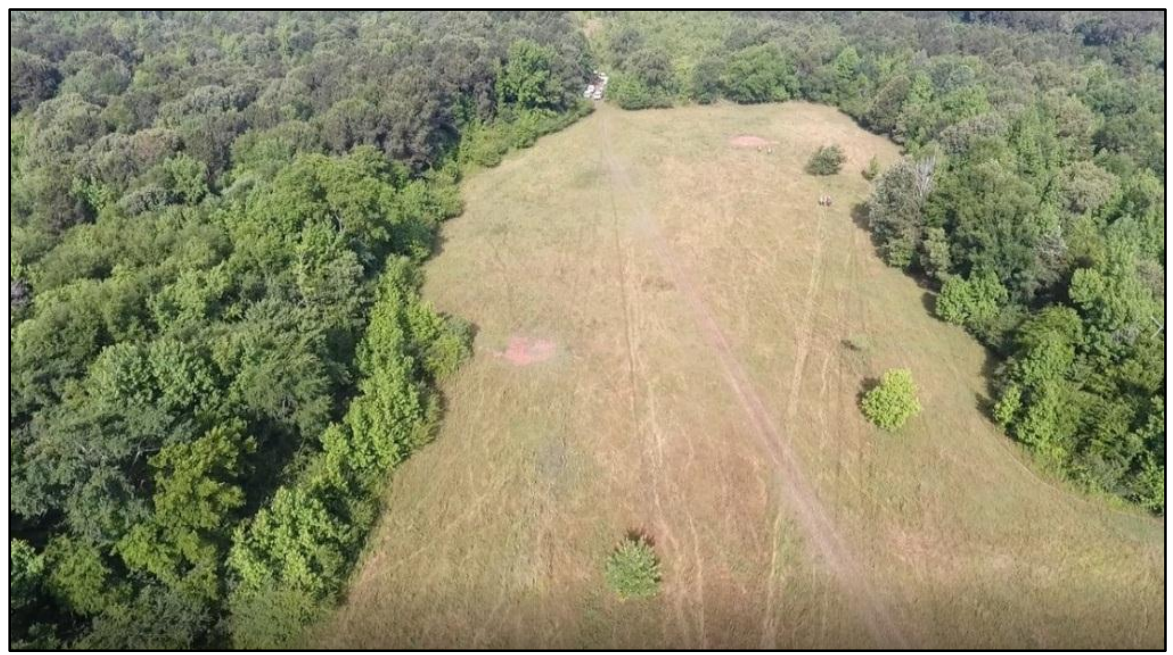

Figure 8. Interactive imagery from the DJI Phantom 4 Advanced drone of the forest opening 


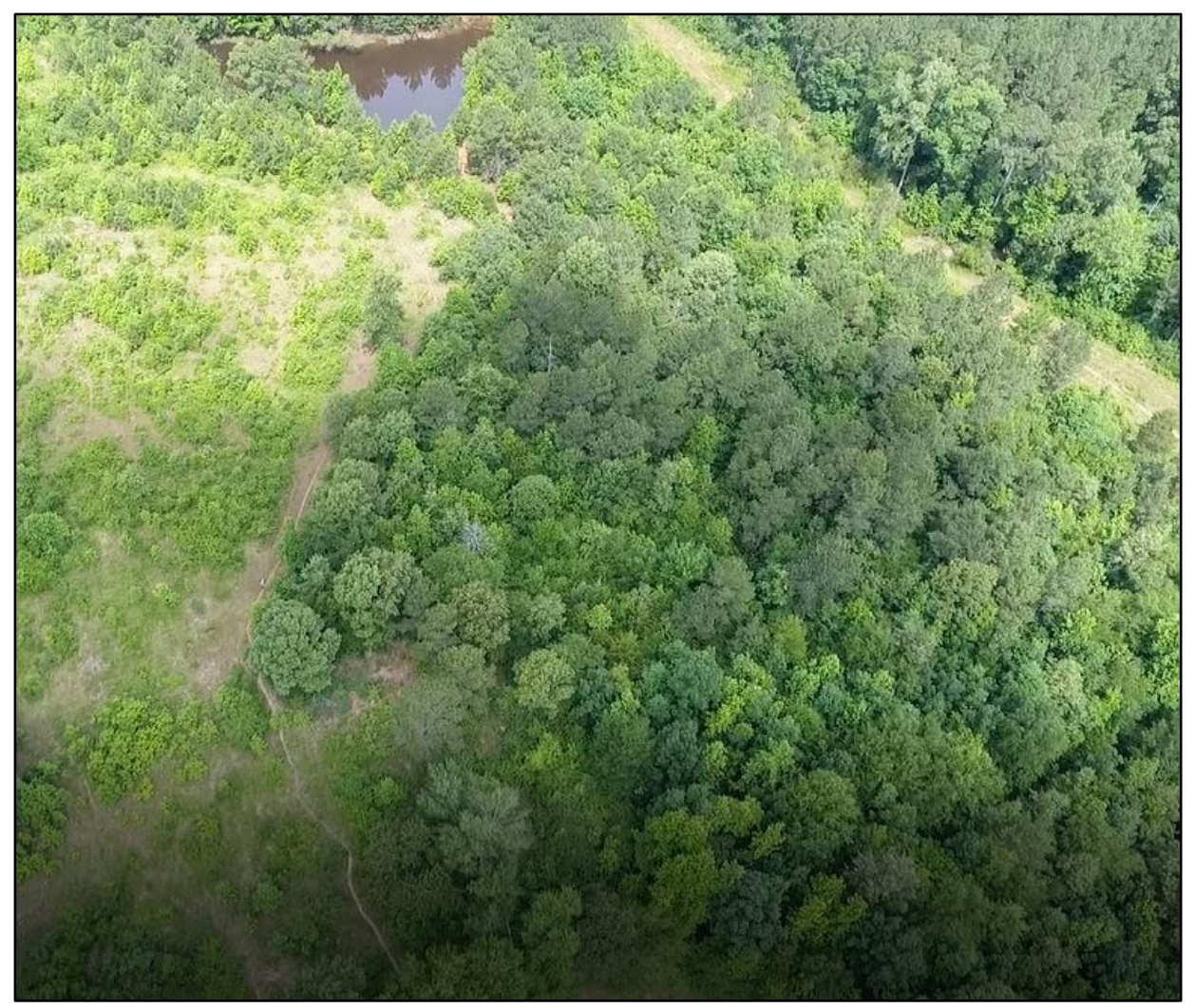

Figure 9. Interactive imagery from the DJI Phantom 4 Advanced drone of the hiking trail

\subsection{GPS Accuracy Validation}

Since the accuracy of the student point coordinates were assessed by calculating RMSE between the student point coordinates and the coordinates of the wooden stake identified via the instructor's GPS unit as well, the RMSE evaluation, although efficient at determining if the students arrived at the correct wooden stake, was insufficient on assessing the actual positional accuracy of each GPS unit utilized in this field exercise.

To validate that the students were recording GPS coordinates correctly, upon returning to the SFA campus each student was asked to record the average UTM coordinated of a known surveyed point on campus. The accuracy of the student GPS data collection procedures were assessed by calculating RMSE between the student point coordinates and the actual surveyed point coordinates of the known survey point on the SFA campus.

In addition to assessing the accuracy of the student GPS data collection procedures, the instructors were able to assess which GPS unit provided the students with the highest accuracy and precision.

\subsection{Report Preparation with Map Validation}

After field data collection was completed, the students were driven back to campus where the students were asked to compile a report that describes in detail what they did with respect to their compass traverse, average point collection, polygon collection, hiking trail collection, and GPS data collection procedures. The reports were assigned one report per group to facilitate discussion and improve communication skills among the students. The reports included a comprehensive introduction, methods, results and discussion sections as well as any accompanying tables, figures, and maps produced (Figure 10). 


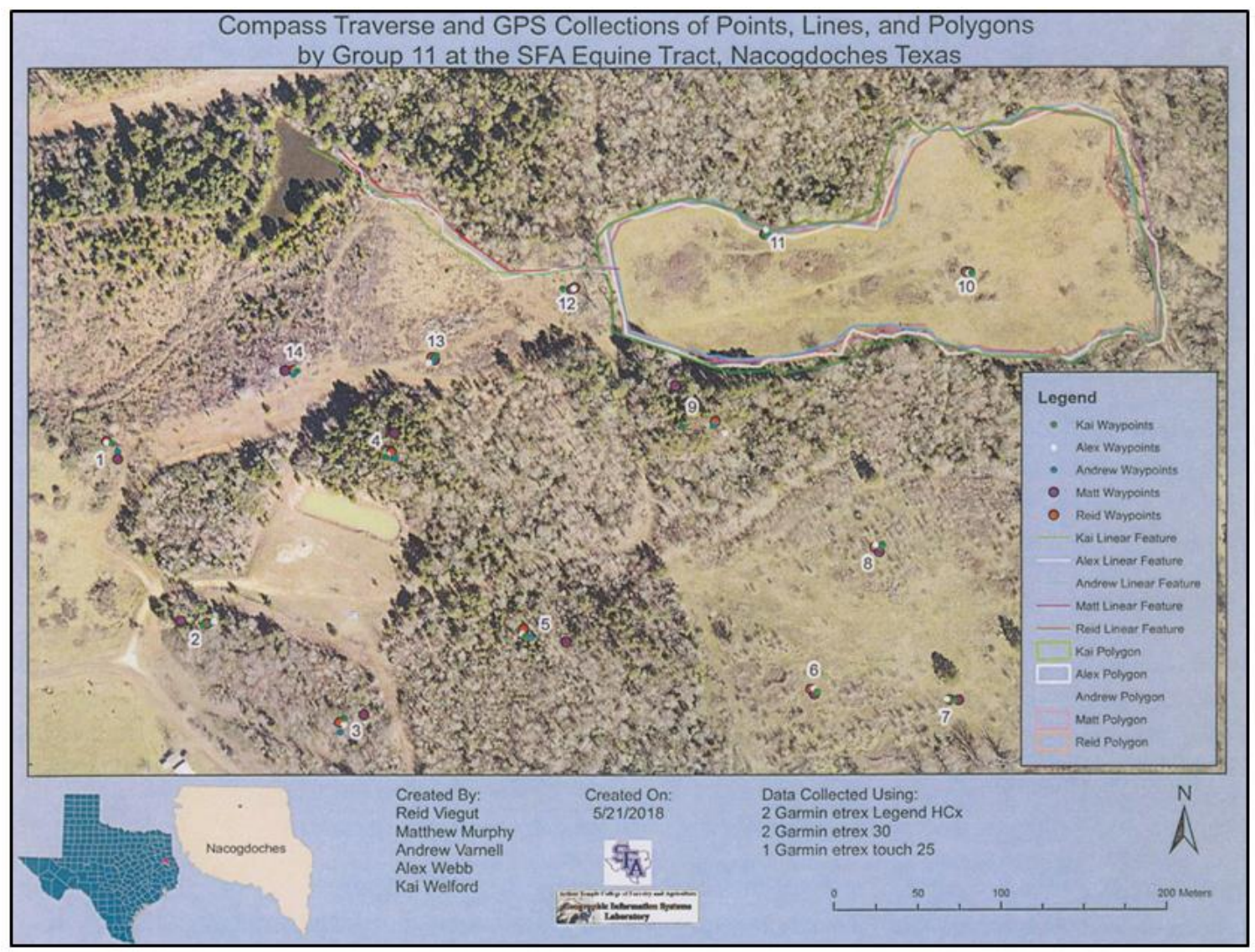

Figure 10. Example of a group's map showing the GPS collected points, hiking trail, and forest opening

\section{Results and Conclusion}

The accuracy of each students transect and compass traverse were evaluated via an RMSE analysis. A summary of individual RMSE between each students point coordinates and the coordinates of the wooden stake that each group should have reached at the end of each of their transect lines is listed in Table 2. Individual student RMSE values ranged from a high of 4,190.67 meters to a low of 4.80 meters; median RMSE of all students was 8.34 meters. Extremely high RMSE for a student indicated that they did not record the geographic coordinates of the correct wooden stake due to an incorrectly calculated azimuth for a transect line, an incorrect calculation of distance walked along a transect line, or incorrect reading of the UTM coordinates. RMSE values close to the median value of 8.34 meters indicates that the student recorded the geographic coordinates of the correct wooden stake.

Table 2. Individual student RMSE values for all 14 wooden stakes stratified by person per group

\begin{tabular}{|c|c|c|c|c|c|c|c|c|c|c|c|c|}
\hline \multirow[t]{2}{*}{$\begin{array}{l}\text { Person } \\
\text { (ID \#) }\end{array}$} & \multicolumn{12}{|c|}{$\begin{array}{c}\text { Group Number } \\
\text { RMSE Per Person (meters) }\end{array}$} \\
\hline & 1 & 2 & 3 & 4 & 5 & 6 & 7 & 8 & 9 & 10 & 11 & 12 \\
\hline 1 & 8.93 & 121.10 & 4190.67 & 6.11 & 51.77 & 8.09 & 12.47 & 6.56 & 8.04 & 5.76 & 6.45 & 5.52 \\
\hline 2 & 15.51 & 8.62 & 8.65 & 6.45 & 203.93 & 8.70 & 9.34 & 4.80 & 6.23 & 5.92 & 8.68 & 5.60 \\
\hline 3 & 10.00 & 26.38 & 6.64 & 6.11 & 9.95 & 8.68 & 46.45 & N/A & 8.31 & 6.26 & 5.95 & 5.12 \\
\hline 4 & 9.99 & 7.80 & 8.58 & 8.34 & 12.40 & 7.34 & 52.28 & N/A & 7.02 & 8.13 & 5.90 & 6.12 \\
\hline 5 & 9.10 & N/A & N/A & N/A & 36.64 & N/A & 19.50 & N/A & N/A & N/A & N/A & N/A \\
\hline
\end{tabular}

To validate that the students were recording geographic point, line, and polygon coordinates correctly with their respective GPS units, upon returning to campus each student calculated the RMSE error between a known survey point on the SFA campus with their GPS derived coordinates of the known survey point location (Tables 
3-5). RMSE error between a student recorded location and the known location were 5.64 meters for the Garmin eTrex Legend HCx, 4.01 meters for the Garmin eTrex 30, and 4.00 meters for the Garmin eTrex Touch 25 GPS units respectfully. The close agreement between all three types of GPS units validates that the students were in fact using their GPS units correctly and further validates that the three different GPS units utilized during the land measurement week of field station were sufficient in recording the geographic coordinates of point, line, and polygon features identified in the field (Unger, Kulhavy, Hung, \& Zhang, 2014).

To assess student retention of the material presented on Monday, a summary of grade received per person for their submitted groups GPS report is stratified by number of students and percentage of class in 2.5 percent equal intervals identified in Table 6. Grades on the report per person resulted in 33 of 56 students (59.0\%) receiving a high A, 14 of 56 students (25.0\%) receiving a low A, and 9 of 56 students (16.0\%) receiving a high B. The student retention results from this study confirms the results found in a previous study by Unger (2014) that the interactive hands-on nature of ATCOFA's field station is effective at providing students with real-world applications whereby they will be ready to make a difference the day after graduation.

Interactive drone imagery and video were also integrated into the daily activities in the field to enhance a student's understanding of their specific objectives, provided the students in the field with a bird's eye perspective of the landscape aid and understand the planning of the field tasks assigned, and provided the instructors imagery and video of the field exercises for further instruction. Student comments at the end of the field measurement week indicated that they felt the drone imagery was very useful in helping evaluating the landscape from a different perspective, that the idea of being able to see and evaluate a field location that was not within immediate viewing distance interactively from a distance was very useful, and that their introduction to drone technology would make them better trained with high-end technology and more competitive in the work force upon graduation.

Table 3. RMSE between the student point coordinates and the actual surveyed point coordinates of the known survey point on the SFA campus when using the Garmin eTrex Legend HCx GPS receiver

\begin{tabular}{|c|c|c|c|c|c|c|c|c|}
\hline \multirow{2}{*}{$\begin{array}{l}\text { Point } \\
\text { Location } \\
\text { (ID) }\end{array}$} & \multicolumn{2}{|c|}{ Actual Point } & \multicolumn{2}{|c|}{ GPS Point } & \multirow{2}{*}{$\begin{array}{c}\text { Easting } \\
\text { Difference } \\
\text { (meters) }\end{array}$} & \multirow{2}{*}{$\begin{array}{l}\text { Northing } \\
\text { Difference } \\
\text { (meters) }\end{array}$} & \multirow{2}{*}{$\begin{array}{c}\text { Euclidean } \\
\text { Difference } \\
\text { (meters) }\end{array}$} & \multirow{2}{*}{$\begin{array}{l}\text { Squared } \\
\text { Error } \\
\text { (meters) }\end{array}$} \\
\hline & $\begin{array}{c}\text { Easting } \\
\text { (meters) }\end{array}$ & $\begin{array}{c}\text { Northing } \\
\text { (meters) }\end{array}$ & $\begin{array}{c}\text { Easting } \\
\text { (meters) }\end{array}$ & $\begin{array}{c}\text { Northing } \\
\text { (meters) }\end{array}$ & & & & \\
\hline 1 & 343865 & 3499850 & 343863 & 3499849 & 2.00 & 1.00 & 2.24 & 5.00 \\
\hline 2 & 343865 & 3499850 & 343861 & 3499856 & 4.00 & -6.00 & 7.21 & 52.00 \\
\hline 3 & 343865 & 3499850 & 343865 & 3499852 & 0.00 & -2.00 & 2.00 & 4.00 \\
\hline 4 & 343865 & 3499850 & 343866 & 3499850 & -1.00 & 0.00 & 1.00 & 1.00 \\
\hline 5 & 343865 & 3499850 & 343864 & 3499850 & 1.00 & 0.00 & 1.00 & 1.00 \\
\hline 6 & 343865 & 3499850 & 343864 & 3499850 & 1.00 & 0.00 & 1.00 & 1.00 \\
\hline 7 & 343865 & 3499850 & 343861 & 3499842 & 4.00 & 8.00 & 8.94 & 80.00 \\
\hline 8 & 343865 & 3499850 & 343861 & 3499848 & 4.00 & 2.00 & 4.47 & 20.00 \\
\hline 9 & 343865 & 3499850 & 343865 & 3499847 & 0.00 & 3.00 & 3.00 & 9.00 \\
\hline 10 & 343865 & 3499850 & 343865 & 3499850 & 0.00 & 0.00 & 0.00 & 0.00 \\
\hline 11 & 343865 & 3499850 & 343864 & 3499850 & 1.00 & 0.00 & 1.00 & 1.00 \\
\hline 12 & 343865 & 3499850 & 343862 & 3499851 & 3.00 & -1.00 & 3.16 & 10.00 \\
\hline 13 & 343865 & 3499850 & 343855 & 3499850 & 10.00 & 0.00 & 10.00 & 100.00 \\
\hline 14 & 343865 & 3499850 & 343866 & 3499847 & -1.00 & 3.00 & 3.16 & 10.00 \\
\hline 15 & 343865 & 3499850 & 343862 & 3499860 & 3.00 & -10.00 & 10.44 & 109.00 \\
\hline 16 & 343865 & 3499850 & 343856 & 3499848 & 9.00 & 2.00 & 9.22 & 85.00 \\
\hline 17 & 343865 & 3499850 & 343864 & 3499853 & 1.00 & -3.00 & 3.16 & 10.00 \\
\hline 18 & 343865 & 3499850 & 343863 & 3499848 & 2.00 & 2.00 & 2.83 & 8.00 \\
\hline 19 & 343865 & 3499850 & 343864 & 3499850 & 1.00 & 0.00 & 1.00 & 1.00 \\
\hline 20 & 343865 & 3499850 & 343856 & 3499850 & 9.00 & 0.00 & 9.00 & 81.00 \\
\hline 21 & 343865 & 3499850 & 343865 & 3499849 & 0.00 & 1.00 & 1.00 & 1.00 \\
\hline 22 & 343865 & 3499850 & 343853 & 3499847 & 12.00 & 3.00 & 12.37 & 153.00 \\
\hline 23 & 343865 & 3499850 & 343865 & 3499846 & 0.00 & 4.00 & 4.00 & 16.00 \\
\hline \multirow[t]{4}{*}{24} & 343865 & 3499850 & 343866 & 3499848 & -1.00 & 2.00 & 2.24 & 5.00 \\
\hline & & & & Mean & 2.67 & 0.38 & 4.31 & 31.79 \\
\hline & & & & SD & 3.71 & 3.44 & 3.71 & 5.64 \\
\hline & & & & & & & & RMSE \\
\hline
\end{tabular}


Table 4. RMSE between the student point coordinates and the actual surveyed point coordinates of the known survey point on the SFA campus when using the Garmin eTrex 30 GPS receiver

\begin{tabular}{crrrrrrrr}
\hline $\begin{array}{c}\text { Point } \\
\text { Location } \\
\text { (ID) }\end{array}$ & $\begin{array}{c}\text { Easting } \\
\text { (meters) }\end{array}$ & $\begin{array}{c}\text { Northing } \\
\text { (meters) }\end{array}$ & $\begin{array}{c}\text { Easting } \\
\text { (meters) }\end{array}$ & $\begin{array}{c}\text { Northing } \\
\text { (meters) }\end{array}$ & $\begin{array}{r}\text { Easting } \\
\text { Difference } \\
\text { (meters) }\end{array}$ & $\begin{array}{r}\text { Northing } \\
\text { Difference } \\
\text { (meters) }\end{array}$ & $\begin{array}{c}\text { Euclidean } \\
\text { Difference } \\
\text { (meters) }\end{array}$ & $\begin{array}{c}\text { Squared } \\
\text { Error } \\
\text { (meters) }\end{array}$ \\
\hline 1 & 343865 & 3499850 & 343862 & 3499851 & 3.00 & -1.00 & 3.16 & 10.00 \\
2 & 343865 & 3499850 & 343863 & 3499851 & 2.00 & -1.00 & 2.24 & 5.00 \\
3 & 343865 & 3499850 & 343863 & 3499847 & 2.00 & 3.00 & 3.61 & 13.00 \\
4 & 343865 & 3499850 & 343863 & 3499851 & 2.00 & -1.00 & 2.24 & 5.00 \\
5 & 343865 & 3499850 & 343865 & 3499850 & 0.00 & 0.00 & 0.00 & 0.00 \\
6 & 343865 & 3499850 & 343864 & 3499849 & 1.00 & 1.00 & 1.41 & 2.00 \\
7 & 343865 & 3499850 & 343865 & 3499845 & 0.00 & 5.00 & 5.00 & 25.00 \\
8 & 343865 & 3499850 & 343870 & 3499847 & -5.00 & 3.00 & 5.83 & 34.00 \\
9 & 343865 & 3499850 & 343863 & 3499850 & 2.00 & 0.00 & 2.00 & 4.00 \\
10 & 343865 & 3499850 & 343862 & 3499849 & 3.00 & 1.00 & 3.16 & 10.00 \\
11 & 343865 & 3499850 & 343863 & 3499855 & 2.00 & -5.00 & 5.39 & 29.00 \\
12 & 343865 & 3499850 & 343864 & 3499851 & 1.00 & -1.00 & 1.41 & 2.00 \\
13 & 343865 & 3499850 & 343859 & 3499849 & 6.00 & 1.00 & 6.08 & 37.00 \\
14 & 343865 & 3499850 & 343864 & 3499852 & 1.00 & -2.00 & 2.24 & 5.00 \\
15 & 343865 & 3499850 & 343863 & 3499847 & 2.00 & 3.00 & 3.61 & 13.00 \\
16 & 343865 & 3499850 & 343862 & 3499849 & 3.00 & 1.00 & 3.16 & 10.00 \\
17 & 343865 & 3499850 & 343863 & 3499850 & 2.00 & 0.00 & 2.00 & 4.00 \\
18 & 343865 & 3499850 & 343856 & 3499852 & 9.00 & -2.00 & 9.22 & 85.00 \\
19 & 343865 & 3499850 & 343860 & 3499851 & 5.00 & -1.00 & 5.10 & 26.00 \\
20 & 343865 & 3499850 & 343864 & 3499849 & 1.00 & 1.00 & 1.41 & 2.00 \\
\hline
\end{tabular}

Table 5. RMSE between the student point coordinates and the actual surveyed point coordinates of the known survey point on the SFA campus when using the Garmin eTrex Touch 25 GPS receiver

\begin{tabular}{cccccrrrr}
\hline $\begin{array}{c}\text { Point } \\
\text { Location } \\
\text { (ID) }\end{array}$ & $\begin{array}{c}\text { Easting } \\
\text { (meters) }\end{array}$ & $\begin{array}{c}\text { Northing } \\
\text { (meters) }\end{array}$ & $\begin{array}{c}\text { Easting } \\
\text { (meters) }\end{array}$ & $\begin{array}{c}\text { Northing } \\
\text { (meters) }\end{array}$ & $\begin{array}{c}\text { Easting } \\
\text { Difference } \\
\text { (meters) }\end{array}$ & $\begin{array}{c}\text { Northing } \\
\text { Difference } \\
\text { (meters) }\end{array}$ & $\begin{array}{c}\text { Euclidean } \\
\text { Difference } \\
\text { (meters) }\end{array}$ & $\begin{array}{c}\text { Squared } \\
\text { Error } \\
\text { (meters) }\end{array}$ \\
\hline 1 & 343865 & 3499850 & 343862 & 3499851 & 3.00 & -1.00 & 3.16 & 10.00 \\
2 & 343865 & 3499850 & 343858 & 3499852 & 7.00 & -2.00 & 7.28 & 53.00 \\
3 & 343865 & 3499850 & 343865 & 3499851 & 0.00 & -1.00 & 1.00 & 1.00 \\
10 & 343865 & 3499850 & 343862 & 3499845 & 3.00 & 5.00 & 5.83 & 34.00 \\
11 & 343865 & 3499850 & 343865 & 3499848 & 0.00 & 2.00 & 2.00 & 4.00 \\
12 & 343865 & 3499850 & 343863 & 3499850 & 2.00 & 0.00 & 2.00 & 4.00 \\
13 & 343865 & 3499850 & 343862 & 3499848 & 3.00 & 2.00 & 3.61 & 13.00 \\
14 & 343865 & 3499850 & 343862 & 3499850 & 3.00 & 0.00 & 3.00 & 9.00 \\
\hline & & & & Mean & $\mathbf{2 . 6 3}$ & $\mathbf{0 . 6 3}$ & $\mathbf{3 . 4 8}$ & 16.00 \\
& & & & SD & 2.20 & 2.26 & 2.10 & $\mathbf{4 . 0 0}$ \\
\hline
\end{tabular}


Table 6. Grade received per person for their group's GPS report stratified by number of students and percentage of class in 2.5 percent equal intervals

\begin{tabular}{ccc}
\hline Report & \multicolumn{2}{c}{ GPS Exercise } \\
\cline { 2 - 3 } (percent) & (number of students) & (percent of class) \\
\hline $97.5-100.0$ & 23 & 41.1 \\
$95.0-<97.5$ & 10 & 17.9 \\
$92.5-<95.0$ & 0 & 0.0 \\
$90.0-<92.5$ & 14 & 25.0 \\
$87.5-<90.0$ & 9 & 16.0 \\
\hline
\end{tabular}

In conclusion, employers can have confidence that when hiring recent BSF graduates from ATCOFA that the students have been introduced to geospatial technologies within a proven one-on-one instruction methodology designed to increase cognitive retention and can traverse from location to location accurately and record the geographic coordinates of earth surface features correctly.

\section{References}

Bullard, S., Stephens Williams, P., Coble, T., Coble, D., Darville, R., \& Rogers, L. (2014). Producing "Society-ready" Foresters: A research-based process to revise the Bachelor of Science in Forestry Curriculum at Stephen F. Austin State University. Journal of Forestry, 112, 354-360. http://dx.doi.org/10.5849/jof.13-098

Clarke, K. (2003). Getting Started with Geographic Information Systems. Upper Saddle River, New Jersey: Prentice Hall.

Federal Aviation Administration. (2016a). Model aircraft operating standards, U. S. Department of Transportation, Federal Aviation Administration, Advisory Circular No.91-57A. Retrieved from https://www.faa.gov/documentLibrary/media/Advisory_Circular/AC_91-57A_Ch_1.pdf

Federal Aviation Administration. (2016b). Summary of small unmanned aircraft rule (Part 107). FAA News, Federal Aviation Administration, Washington, D.C. Retrieved from https://www.faa.gov/uas/media/Part_107_Summary.pdf

Federal Aviation Administration. (2018) Federal Administration Aviation, Unmanned Aircraft Systems. Retrieved from https://www.faa.gov/uas/getting_started/

Heit, L., \& Shortreid, A. (1991). GIS Applications in Natural Resources. Loveland, Colorado: J. L. Printing.

Kulhavy, D., Unger, D., Grisham, R., Coble, D., Endsley, G., \& Gannon, M. (2016). Service learning for the Port Jefferson History and Nature Center: Senior capstone forestry course. Journal of Community Engagement and Higher Education, 9(2), 67-79.

Kulhavy, D., Unger, D., Hung, I., \& Zhang, Y. (2016). Comparison of AR.Drone quadricopter video and the visual CTLA method for urban tree hazard rating. Journal of Forestry, 114. http://dx.doi.org/10.5849/jof.15-005

Lang, L. (1998). Managing Natural Resources with GIS. Redlands, California: ESRI.

Piedallu, C., \& Gegout, J. (2005). Effect of forest environment and survey protocol on GPS accuracy. Photogrammetric Engineering \& Remote Sensing, 71(9), 1071-1078. http://dx.doi.org/10.14358/PERS.71.9.1071

Society of American Foresters. (2011). Accreditation handbook: Standards, procedures, and guidelines for accrediting educational programs in professional forestry. Society of American Foresters, Bethesda, MD. $47 \mathrm{p}$.

Unger, D. (2014). Validating One-On-One GPS Instruction methodology for natural resource area assessments using forestry undergraduate students. Higher Education Studies, 4(1), 94-102. http://dx.doi.org/10.5539/hes.v4n1p94

Unger, D., Hung, I., Zhang, Y., Parker, J., Kulhavy, D., \& Coble, D. (2013). Accuracy assessment of perimeter and area calculations using consumer-grade global positioning system (GPS) units in southern forests. Southern Journal of Applied Forestry, 37, 208-215. http://dx.doi.org/10.5849/sjaf.13-006

Unger, D., Hung, I., Zhang, Y., \& Kulhavy, D. L. (2014). Evaluating GPS effectiveness for natural resource 
professionals: Integrating undergraduate students in the decision-making process. Journal of Studies in Education, 4(4), 30-44. https://doi.org/10.5296/jse.v4i4.6389

Unger, D., Kulhavy, D., Hung, I., \& Zhang, Y. (2014). Quantifying natural resources using field-based instruction and hands-on applications. Journal of Studies in Education, 4(2), 1-14.

https://doi.org/10.5296/jse.v4i2.5309

Unger, D., Kulhavy, D., Busch-Petersen, K., \& Hung, I. (2016). Integrating faculty led service learning training to quantify height of natural resources from a spatial science perspective. International Journal of Education, 5(3), 104-116. https://doi.org/10.5430/ijhe.v5n3p104

Watts, A., Ambrosia, V., \& Hinkley, E. (2012). Unmanned aircraft systems in remote sensing and scientific research: Classification and considerations of use. Remote Sensing, 4(6), 1671-1692. https://doi.org/10.3390/rs4061671

Zheng, J., Wang, Y., \& Nihan, N. (2005). Quantitative evaluation of GPS performance under forest canopies. IEEE Networking, Sensing and Control Conference (IEEE Cat. No. 05EX967), 777-782.

\section{Copyrights}

Copyright for this article is retained by the author(s), with first publication rights granted to the journal.

This is an open-access article distributed under the terms and conditions of the Creative Commons Attribution license (http://creativecommons.org/licenses/by/4.0/). 